Article

\title{
Synthesis, Single Crystal X-Ray Structure, Hirshfeld Surface Analysis, DFT Computations, Docking Studies on Aurora Kinases and an Anticancer Property of 3-(2,3-Dihydrobenzo[b][1,4]dioxin-6-yl)-6- methoxy-4H-chromen-4-one
}

\author{
Seunghyun Ahn ${ }^{1,+}$, Jiha Sung ${ }^{1,+}$, Ji Hye Lee ${ }^{1}$, Miri Yoo ${ }^{1}$, Yoongho Lim ${ }^{2}$, Soon Young Shin ${ }^{3, *(D)}$ \\ and Dongsoo Koh ${ }^{1, *(\mathbb{D})}$ \\ 1 Department of Applied Chemistry, Dongduk Women's University, Seoul 02748, Korea; \\ mistahn321@naver.com (S.A.); sung@dongduk.ac.kr (J.S.); dwg1993@naver.com (J.H.L.); \\ mil2425@naver.com (M.Y.) \\ 2 Division of Bioscience and Biotechnology, BBRC, Konkuk University, Seoul 05029, Korea; \\ yoongho@konkuk.ac.kr \\ 3 Department of Biological Chemistry, Konkuk University, Seoul 05029, Korea \\ * Correspondence: shinsy@konkuk.ac.kr (S.Y.S.); dskoh@dongduk.ac.kr (D.K.) \\ + S.A. and J.S. contributed equally to this work.
}

Received: 20 April 2020; Accepted: 19 May 2020; Published: 20 May 2020

check for updates

\begin{abstract}
The isoflavone compound 3-(2,3-dihydrobenzo[b][1,4]dioxin-6-yl)-6-methoxy-4H-chromen4-one (6) was prepared and structurally characterized using NMR, mass spectrum and X-ray crystallography. Compound $6, \mathrm{C}_{18} \mathrm{H}_{14} \mathrm{O}_{5}$, was crystallized in the monoclinic space group $P 2{ }_{1} / \mathrm{n}$ with the cell parameters; $\mathrm{a}=7.1869(4) \AA, \mathrm{b}=10.2764(6) \AA, \mathrm{c}=19.6771(10) \AA, \beta=99.442(2)^{\circ}, \mathrm{V}=1433.57(14)$ $\AA^{3}, Z=4$. In the title compound, the chromenone ring system is slightly twisted from planarity and the dihedral angle formed between the plane of the chromenone ring and benzene ring is $47.75^{\circ}$. Several intermolecular hydrogen bonds make the crystal stabilized in the three-dimensional structure, which was confirmed by Hirshfeld surface analysis. Density functional theory (DFT) calculations at the B3LYP/6-311++G(d,p) level were carried out and the calculated geometric parameters were compared with the experimental results. A frontier molecular orbital calculation was performed to reveal that the energy values of highest occupied molecular orbital (HOMO) and lowest un-occupied molecular orbital (LUMO) were $-5.8223 \mathrm{eV}$ and $-1.8447 \mathrm{eV}$, and the HOMO-LUMO energy gap was $3.9783 \mathrm{eV}$. A clonogenic long-term survival assay of compound 6 against HCT116 human colon cancer cells showed an anti-cancer ability, with $\mathrm{GI}_{50}$ value of $24.9 \mu \mathrm{M}$. Docking experiments within the active sites of aurora kinase A and B were carried out to explain the anti-cancer property of compound 6.
\end{abstract}

Keywords: isoflavone; crystal structure; hydrogen bonding; in silico docking; Hirshfeld surface; DFT

\section{Introduction}

Flavonoids are widely distributed in plants, performing interactions as secondary metabolites. One of the characteristic flavonoid features is phytoalexins, which show self-defense abilities in plants. The self-defense system of flavonoids has been extensively modified to apply it to medicinal chemistry and has demonstrated antioxidant, anti-proliferative, anti-tumor, anti-microbial, anti-inflammatory and anti-cardiovascular disease properties [1-8]. In the context of chemical structure, flavonoids are phenyl-substituted chromones which are divided into flavones and isoflavones depending on the site of substituents in the chromone ring [9]. 
The target identification of bioactive compounds is a significant step in medicinal chemistry for the development of new drugs which have unique modes of action. A recent review describes that flavones are one of the most important scaffolds for medicinal chemistry and their applications in pharmaceutical research are extremely diverse [10]. In silico methods, such as molecular docking, have been widely used in the target research of bioactive compounds, and the complete three-dimensional structures of substrates and proteins are the prerequisites for these processes [11-13].

In continuation of our previous research on flavones and isoflavones [14-17], and in order to expand their applications in target validation research, isoflavone compound $\mathbf{6}$ was synthesized and the structure was confirmed by X-ray crystallographic analyses. With the three-dimensional structure of isoflavone derivative 6 in hand, molecular docking studies on aurora kinases were performed to widen the molecular targets and to give insight on the mode of action for anti-cancer activities.

\section{Materials and Methods}

\subsection{General}

NMR experiments were carried out on a Bruker Avance 400 spectrometer. The concentrations of the samples were adjusted to approximately $50 \mathrm{mM}$ dissolved in deuterated dimethyl sufoxide $\left(\right.$ DMSO- $\left.d_{6}\right)$. The detailed procedures and parameters for the experiments followed the methods reported previously [18]. The ${ }^{1} \mathrm{H}-\mathrm{NMR}$ spectrum data were collected at room temperature, and the relaxation delay, $90^{\circ}$ pulse, spectral width, number of data points and digital resolution were $1 \mathrm{~s}$, $11.6 \mu \mathrm{s}, 5500 \mathrm{~Hz}, 32 \mathrm{~K}$, and $0.34 \mathrm{~Hz} /$ point, respectively. For the ${ }^{13} \mathrm{C}-\mathrm{NMR}$ spectrum, the proton signals were decoupled with broadband decoupling. The relaxation delay, $90^{\circ}$ pulse, spectral width, number of data points and digital resolution were $3 \mathrm{~s}, 15.0 \mu \mathrm{s}, 21,000 \mathrm{~Hz}, 64 \mathrm{~K}$, and $0.64 \mathrm{~Hz} /$ point, respectively. To get a high-resolution mass spectrum, ultra performance liquid chromatography-hybrid quadrupole time-of-flight mass spectrometry was carried out on a Waters Acquity UPLC system (Waters Corp., Milford, MA, USA). All HR/MS data were collected in $[\mathrm{M}+\mathrm{H}]^{+}$mode. Thin layer chromatography (TLC) plates from Merck (silica gel pre-coated aluminum cards with fluorescent indicator at $254 \mathrm{~nm}$ ) were used for TLC. Visualization was performed by illumination with UV light source $(254 \mathrm{~nm})$. All the commercially available chemicals were purchased from Sigma-Aldrich (St. Louis, MO, USA) [12].

\subsection{Crystal Structure Determination}

A Bruker D8 Venture (Bruker, Madison, WI, USA) equipped with an $\mathrm{I} \mu \mathrm{S}$ micro-focus sealed tube Mo K $\alpha(\lambda=0.71073 \AA)$ and a PHOTON 100 CMOS detector was used to collect data. Single crystals were obtained by slow evaporation of the ethanol solution of isoflavone 6 at an ambient temperature. A Bruker SAINT was utilized for cell refinement and data reduction [19]. The structure was solved by direct methods and refined by full-matrix least-squares on $F^{2}$ using SHELXTL [20]. All non-hydrogen atoms were located on different Fourier maps and refined anisotropically. The C-H hydrogen atoms were positioned with idealized geometry and were refined with fixed isotropic displacement parameters $U_{\text {iso }}(\mathrm{H})=1.2 U_{\text {eq }}(\mathrm{C})$ for aromatic and $U_{\text {iso }}(\mathrm{H})=1.5 U_{\text {eq }}(\mathrm{C})$ for methyl $\mathrm{H}$ atoms using a riding model. Details of the crystallographic data collection, structural determination and refinement are summarized in Table 1. CCDC deposition number 1989319 contains the supplementary crystallographic data for this paper, which can be obtained free of charge from the CCDC, 12 Union Road, Cambridge CB2 1EZ, UK; Fax: +44 1223 336033; E-mail: deposit@ccdc.cam.ac.uk. 
Table 1. Crystal data and structure refinement for Compound 6.

\begin{tabular}{|c|c|}
\hline Empirical formula & $\mathrm{C}_{18} \mathrm{H}_{14} \mathrm{O}_{5}$ \\
\hline Formula weight & 310.29 \\
\hline Temperature & 223(2) K \\
\hline Wavelength & $0.71073 \AA$ \\
\hline Crystal system & Monoclinic \\
\hline Space group & $\begin{array}{c}P 2_{1} / \mathrm{n} \\
\mathrm{a}=7.1869(4) \AA\end{array}$ \\
\hline Unit cell dimensions & $\begin{array}{c}\mathrm{b}=10.2764(6) \AA \\
\mathrm{c}=19.6771(10) \AA \\
\beta=99.442(2)^{\circ}\end{array}$ \\
\hline Volume & $1433.57(14) \AA^{3}$ \\
\hline Z & 4 \\
\hline Density (calculated) & $1.438 \mathrm{Mg} / \mathrm{m}^{3}$ \\
\hline Absorption coefficient & $0.106 \mathrm{~mm}^{-1}$ \\
\hline $\mathrm{F}(000)$ & 648 \\
\hline Crystal size & $0.190 \times 0.150 \times 0.100 \mathrm{~mm}^{3}$ \\
\hline Theta range for data collection & 2.098 to $28.296^{\circ}$ \\
\hline Index ranges & $-9 \leq \mathrm{h} \leq 9,-13 \leq \mathrm{k} \leq 13,-26 \leq 1 \leq 26$ \\
\hline Reflections collected & 39243 \\
\hline Independent reflections & $3573[\mathrm{R}(\mathrm{int})=0.0491]$ \\
\hline Completeness to theta $=25.242^{\circ}$ & $100.00 \%$ \\
\hline Refinement method & Full-matrix least-squares on $\mathrm{F}^{2}$ \\
\hline Data / restraints / parameters & $3573 / 0 / 209$ \\
\hline Goodness-of-fit on $\mathrm{F}^{2}$ & 1.039 \\
\hline Final $R$ indices $[\mathrm{I}>2 \operatorname{sigma}(\mathrm{I})]$ & $\mathrm{R} 1=0.0396, \mathrm{wR} 2=0.0990$ \\
\hline $\mathrm{R}$ indices (all data) & $\mathrm{R} 1=0.0577, \mathrm{wR} 2=0.1083$ \\
\hline Largest diff. peak and hole & 0.347 and -0.183 e. $\AA^{-3}$ \\
\hline
\end{tabular}

\subsection{In Silico Docking with Aurora Kinases}

In silico dockings to elucidate the molecular binding mode between isoflavone 6 and aurora kinase A and B (AURKA and AURKB) were performed on an Intel Core 2 Quad Q6600 (2.4 GHz) Linux PC with Sybyl 7.3 (Tripos, St. Louis, MO, USA). The 3D structure of AURKA was adopted from the X-ray crystallographic structure deposited in the protein data bank as 3uod.pdb [21]. Although it is not the 3D structure containing the greatest number of residues (2j4z.pdb) [22], because the ligand contained in this 3D structure is similar to the current compound, 3uod.pdb was selected. Unlike AURKA, AURKB was rarely studied for its 3D structures, so 4af3.pdb was chosen from the protein databank [23].

\section{Results and Discussion}

\subsection{Synthesis}

The isoflavone compound $\mathbf{6}$ was prepared according to literature methods as shown in Scheme 1 [24,25]. Synthesis of 3-iodo-6-methoxy-4H-chromen-4-one (4)

2-hydroxy-5-methoxyacetophenone $(\mathbf{1}, 1.66 \mathrm{~g}, 10 \mathrm{mmol})$ was dissolved in an excess amount of $\mathrm{N}, \mathrm{N}$-dimethylformamide dimethyl acetal $(2,4.5 \mathrm{~mL}, 21.1 \mathrm{mmol})$ and the reaction mixture was heated at $75^{\circ} \mathrm{C}$ for $1 \mathrm{~h}$. After the completion of the reaction (checked by TLC), the reaction mixture was cooled down to room temperature to give precipitates. The resulting solid was filtered and washed with cold methanol to give intermediate enamine (3) which was used for the next reaction without further purification. Enamine (3, $2.0 \mathrm{~g}, 7.9 \mathrm{mmol})$ was dissolved in $\mathrm{MeOH}(10 \mathrm{~mL})$. To the solution, a 1.1 equivalent amount of iodine $(2.22 \mathrm{~g}, 8.8 \mathrm{mmol})$ was added and the reaction mixture was stirred at room temperature overnight. After the completion of the reaction, precipitation was formed. The resulting solid was filtered and washed with cold methanol to provide a solid compound of iodoflavone $(4) .{ }^{1} \mathrm{H}$ NMR $\left(400 \mathrm{MHz}, \mathrm{DMSO}_{-} \mathrm{d}_{6}\right) \delta 8.81(\mathrm{~s}, 1 \mathrm{H}), 7.64(\mathrm{dd}, 1 \mathrm{H}, J=9.0,0.5 \mathrm{~Hz}), 7.42(\mathrm{~d}, 1 \mathrm{H}, J=3.2 \mathrm{~Hz}), 7.40$ 
$(\mathrm{d}, 1 \mathrm{H}, J=0.5 \mathrm{~Hz}), 3.86(\mathrm{~s}, 3 \mathrm{H},) ;{ }^{13} \mathrm{C}$ NMR $\left(100 \mathrm{MHz}, \mathrm{DMSO}-d_{6}\right) \delta 172.57,158.85,156.84,150.42,123.66$, $121.78,120.00,105.14,85.80,55.77$.

Synthesis of 3-(2,3-dihydrobenzo[b][1,4]dioxin-6-yl)-6-methoxy-4H-chromen-4-one (6)

3-Iodo flavone compound (4, $60 \mathrm{mg}, 0.2 \mathrm{mmol})$ was dissolved in $20 \mathrm{ml}$ of a methanol-water (1:1) solution. To the solution was added PEG $(750 \mathrm{mg})$ and sodium carbonate $(45 \mathrm{mg}, 0.45 \mathrm{mmol})$ and it was stirred for $1 \mathrm{~h}$. To the reaction mixture, a catalytic amount of palladium(II) acetate and (2,3-dihydrobenzo[b][1,4]dioxin-6-yl) boronic acid (5, $40 \mathrm{mg}, 0.3 \mathrm{mmol})$ were added, and the resulting mixture was heated at $50^{\circ} \mathrm{C}$ for $1 \mathrm{~h}$. After the completion of the reaction (checked by TLC), the reaction mixture was cooled down to room temperature and the organic solvent was removed by evaporation. The resulting suspension was extracted with $\mathrm{CH}_{2} \mathrm{Cl}_{2}(10 \mathrm{~mL} \times 3)$. The organic phase was dried over $\mathrm{MgSO}_{4}$ and was filtered. The filtrate was evaporated, and the resulting residue was purified by flash chromatography to give an analytically pure compound of $6 .{ }^{1} \mathrm{H}$ NMR $\left(400 \mathrm{MHz}, \mathrm{DMSO}-d_{6}\right) \delta 8.48$ $(\mathrm{s}, 1 \mathrm{H}), 7.65(\mathrm{~d}, 1 \mathrm{H}, J=9.1 \mathrm{~Hz}), 7.50(\mathrm{~d}, 1 \mathrm{H}, J=3.1 \mathrm{~Hz}), 7.42(\mathrm{dd}, 1 \mathrm{H}, J=9.1,3.2 \mathrm{~Hz}), 7.15(\mathrm{~d}, 1 \mathrm{H}$, $J=2.1 \mathrm{~Hz}), 7.07(\mathrm{dd}, 1 \mathrm{H}, J=8.4,2.1 \mathrm{~Hz}), 6.91(\mathrm{~d}, 1 \mathrm{H}, J=8.3 \mathrm{~Hz}), 4.27(\mathrm{~s}, 4 \mathrm{H}), 3.87(\mathrm{~s}, 3 \mathrm{H}) ;{ }^{13} \mathrm{C} \mathrm{NMR}$ $\left(100 \mathrm{MHz}, \mathrm{DMSO}-d_{6}\right) \delta 174.80,156.56,153.99,150.28,143.21,142.93,124.89,124.43,123.29,122.38$, $121.73,119.93,117.57,116.71,105.13,64.14,64.03,55.71 ; \mathrm{HR} / \mathrm{MS}(\mathrm{m} / \mathrm{z})$ : Calcd. for $(\mathrm{M}+\mathrm{H})^{+}$: 311.0919; Found: 311.0914 .<smiles>COc1ccc(O)c(C(C)=O)c1</smiles><smiles>COc1ccc2occ(I)c(=O)c2c1</smiles>

4

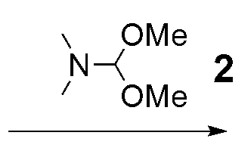<smiles>Oc1ccc2c(c1)OCCO2</smiles>

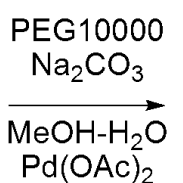

$\mathrm{Pd}(\mathrm{OAC})_{2}$<smiles>COc1ccc2occ(-c3ccc4c(c3)OCCO4)c(=O)c2c1</smiles>

6

Scheme 1. Synthetic scheme for the preparation of isoflavone compound $\mathbf{6}$ from commercially available starting materials.

\subsection{Crystal Structure of Isoflavone Compound 6}

Isoflavone compound 6 crystallized in the monoclinic system with $P 2_{1} / n$ space group. The molecular structure based on single-crystal X-ray studies is shown in Figure 1A. In the middle of the unit cell, two molecules are stacked by pi-pi stacking between the two chromenone ring systems (C1-C9/O1). The distance between two centroids $(\mathrm{Cg} 1=\mathrm{C} 2-\mathrm{C} 3-\mathrm{C} 4-\mathrm{C} 5-\mathrm{C} 6-\mathrm{C} 7, \mathrm{Cg} 2=$ C1-C2-C7-O2-C8-C9) is $3.678 \AA$. The asymmetric unit cell of compound 6 and the crystal packing image is shown in Figure 1B. 


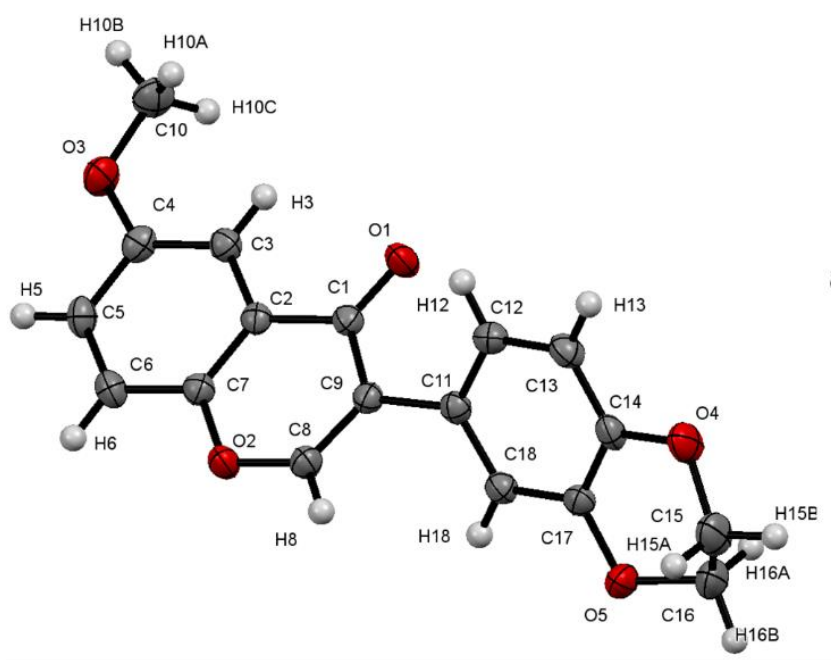

A

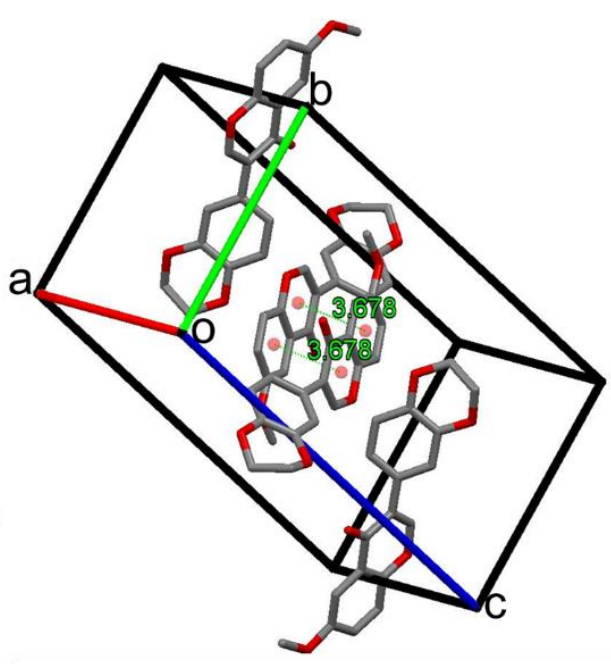

B

Figure 1. Crystal structure with the label of isoflavone 6 (A) and its crystal packing image in a unit cell (B). All hydrogens are omitted for clarity in (B).

In the title compound, the methoxy groups in the chromenone ring at $\mathrm{C} 4$ is tilted from the ring by $-5.81^{\circ}$. The benzene ring attached at $\mathrm{C} 9$ position of the chromenone ring is fused with two oxo-methylene substituents $\mathrm{C} 14$ and $\mathrm{C} 17$ to form a dihydrobenzo[b]dioxin ring. The dioxin ring forms a half-chair conformation in which the atom $\mathrm{C} 16$ shows maximum deviation from the dioxane ring of C15-C16-O5-C17-C14-O4 (root-mean-square deviation = $0.195 \AA$ ) by 0.317(1) $\AA$. Each methylene carbon $\mathrm{C} 14$ and $\mathrm{C} 17$ contains two hydrogens, respectively, and their dihedral angles across the carbon C14-C17 are $179.1^{\circ}$ (H16A-C16-C15-H15A, anti-periplanar), -62.5 (H16A-C16-C15-H15B, gauche) and $-62.3^{\circ}$ (H15A-C15-C16-H16B, gauche). Selected dihedral angles across the free rotational C-C single bonds are listed in Table 2.

Table 2. Selected dihedral angles $\left[{ }^{\circ}\right]$ for isoflavone compound 6.

\begin{tabular}{cc}
\hline $\mathrm{C}(10)-\mathrm{O}(3)-\mathrm{C}(4)-\mathrm{C}(3)$ & $-5.8(2)$ \\
$\mathrm{C}(17)-\mathrm{C}(14)-\mathrm{O}(4)-\mathrm{C}(15)$ & $-12.8(2)$ \\
$\mathrm{C}(14)-\mathrm{C}(17)-\mathrm{O}(5)-\mathrm{C}(16)$ & $-15.9(2)$ \\
$\mathrm{C}(10)-\mathrm{O}(3)-\mathrm{C}(4)-\mathrm{C}(3)$ & $-5.8(2)$ \\
$\mathrm{C}(7)-\mathrm{C}(2)-\mathrm{C}(1)-\mathrm{C}(9)$ & $-3.1(2)$ \\
$\mathrm{H}(16 \mathrm{~A})-\mathrm{C}(16)-\mathrm{C}(15)-\mathrm{H}(15 \mathrm{~A})$ & 179.1 \\
$\mathrm{H}(15 \mathrm{~A})-\mathrm{C}(15)-\mathrm{C}(16)-\mathrm{H}(16 \mathrm{~B})$ & -62.3 \\
$\mathrm{H}(16 \mathrm{~A})-\mathrm{C}(16)-\mathrm{C}(15)-\mathrm{H}(15 \mathrm{~B})$ & -62.5 \\
$\mathrm{H}(16 \mathrm{~B})-\mathrm{C}(16)-\mathrm{C}(15)-\mathrm{H}(15 \mathrm{~B})$ & 56.1 \\
\hline
\end{tabular}

In the title compound, the chromenone ring system (C1-C9/O1) is slightly twisted from planarity, with a maximum deviation of $0.024 \AA$ at C- 1 (root-mean-square deviation $=0.016 \AA$ ). The dihedral angle formed between the plane of the chromenone ring and benzene (C11-C18) ring is $47.75^{\circ}$ (Figure 2). It shows a good contrast with our previous reports on flavonoids, which described that the angle formed between the plane of the chromenone ring and benzene ring is $5.2(4)^{\circ}$, which makes two planes parallel [26], and that of the chromenone ring and naphthalene ring is $88.96(3)^{\circ}$ making two planes orthogonal, respectively [27]. 


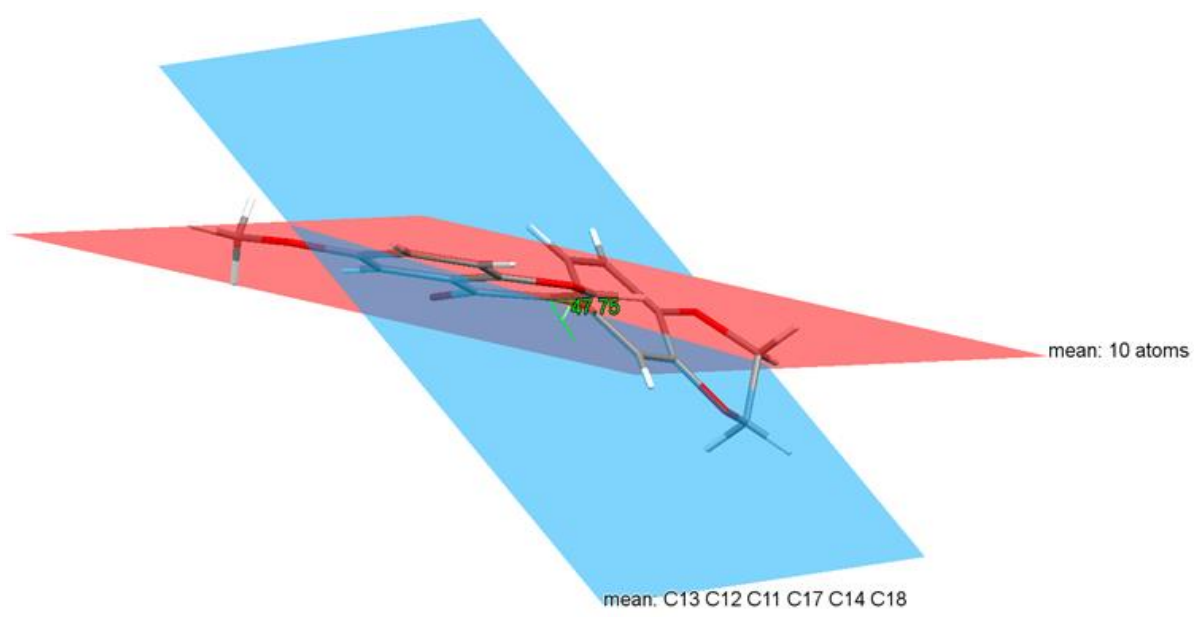

Figure 2. Dihedral angle formed between the plane of the chromenone ring (red) and benzene ring (blue).

Hydrogen bonds play an important role in stabilizing the 3D framework structure. In the crystal, pairs of $\mathrm{C}(10)-\mathrm{H}(10 \mathrm{~B}) \cdots \mathrm{O}(3) \# 2$ (Symmetry transformations \#2; $-\mathrm{x},-\mathrm{y}+3,-\mathrm{z}$ ) hydrogen bonds form inversion dimers with graph-set notation $\mathrm{R}^{2}{ }_{2}(6)$. The dimers are linked into chains along the b-axis direction by pairs of the $\mathrm{C}(13)-\mathrm{H}(13) \cdots \mathrm{O}(1) \# 1(\# 1 ;-\mathrm{x}+1 / 2, \mathrm{y}-1 / 2,-\mathrm{z}+1 / 2)$ hydrogen bonds (Figure 3, Table 3).

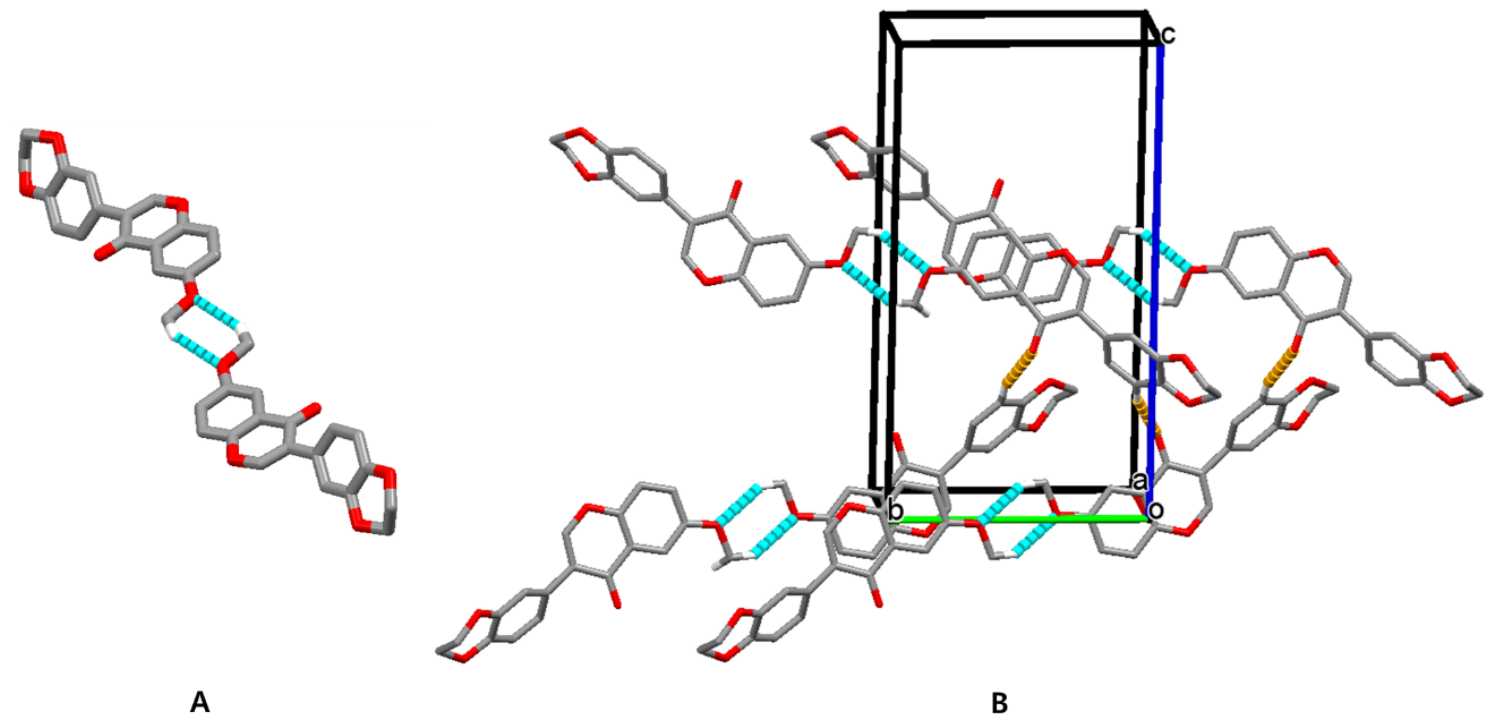

Figure 3. Pairs of hydrogen bonds form an inversion dimer (A) which are linked into chains along the b-axis (B).

Table 3. Intermolecular hydrogen bonds for isoflavone 6 [ $\left[{ }^{\circ}\right.$ and $\left.{ }^{\circ}\right]$.

\begin{tabular}{ccccc}
\hline $\mathbf{D}-\mathbf{H} \cdots \mathbf{A}$ & $\mathbf{d}(\mathbf{D}-\mathbf{H})$ & $\mathbf{d}(\mathbf{H} \cdots \mathbf{A})$ & $\mathbf{d}(\mathbf{D} \cdots \mathbf{A})$ & $<$ (DHA) \\
\hline $\mathrm{C}(13)-\mathrm{H}(13) \cdots \mathrm{O}(1) \# 1$ & 0.94 & 2.48 & $3.3970(17)$ & 163.8 \\
$\mathrm{C}(10)-(10 \mathrm{~B}) \cdots \mathrm{O}(3) \# 2$ & 0.97 & 2.55 & $3.4005(19)$ & 146.9 \\
$\mathrm{C}(6)-\mathrm{H}(6) \cdots \mathrm{O}(4) \# 3$ & 0.94 & 2.61 & $3.2639(17)$ & 127.0 \\
$\mathrm{C}(16)-(16 \mathrm{~A}) \cdots \mathrm{O}(1) \# 4$ & 0.98 & 2.62 & $3.581(2)$ & 168.2 \\
\hline
\end{tabular}

Symmetry transformations used to generate equivalent atoms: $\# 1-x+1 / 2, y-1 / 2,-z+1 / 2, \# 2-x,-y+3,-z, \# 3 x-1 / 2$, $-\mathrm{y}+3 / 2, \mathrm{z}-1 / 2, \# 4-\mathrm{x}+3 / 2, \mathrm{y}-1 / 2,-\mathrm{z}+1 / 2$. 
Additional intermolecular hydrogen bonds $\mathrm{C}(6)-\mathrm{H}(6) \cdots \mathrm{O}(4) \# 3$ (\#3; $\mathrm{x}-1 / 2,-\mathrm{y}+3 / 2, \mathrm{z}-1 / 2)$ link molecules into chains propagating along the c-axis direction. Three dimensional molecular packings in the crystal are shown in Figure 4. The lengths $(\AA)$ and angles $\left(^{\circ}\right)$ of intermolecular hydrogen bonds for isoflavone 6 are listed in Table 3.

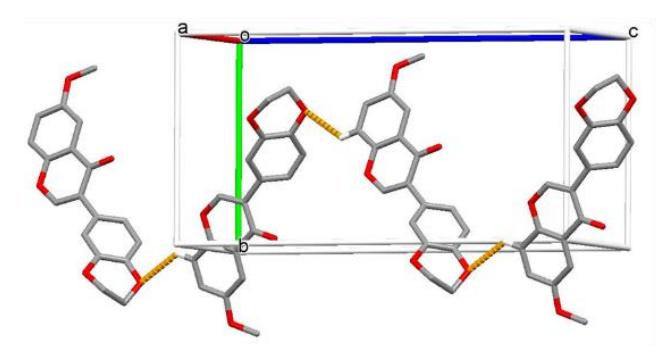

A

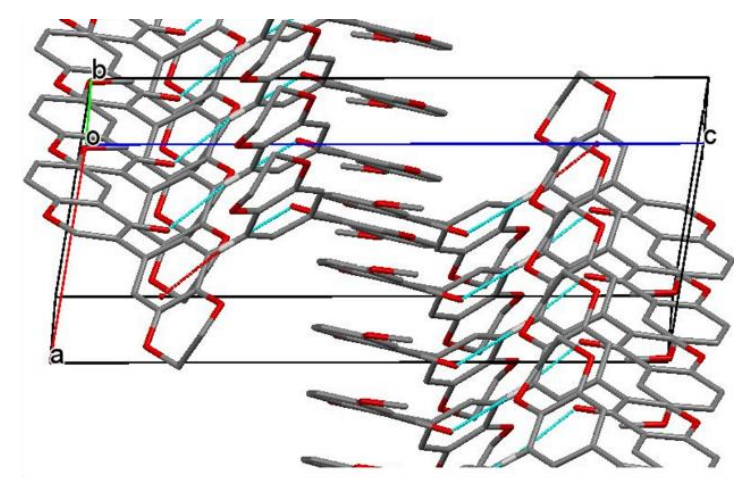

B

Figure 4. Intermolecular hydrogen bonds lead the molecules along c-axis (A) and multiple intermolecular hydrogen bonds stabilize crystal packing by a three-dimensional network (B).

\subsection{Hirshfeld Surface Analysis}

In order to analyze the intermolecular interactions in the crystal, Hirshfeld surface (HS) analysis was carried out using Crystal Explorer 17.5 [28,29]. The 3D Hirshfeld surfaces of the title compound are illustrated in Figure $5 \mathrm{~A}$, which maps $d_{\text {norm }}$, shape index and curvedness. The normalized contact distances (dnorm) were mapped into the Hirshfeld surface, which enabled the visualization of intermolecular interactions by using different colors. In the $d_{\text {norm }}$ Hirshfeld surface, white indicate contacts equal to the sum of van der Waals radii, the red spots indicate the close contact interactions, and blue is for longer contacts. As shown in Figure 5B, the deep red spots on the $d_{\text {norm }}$ Hirshfeld surface represent the close contact interactions, which are mainly responsible for the significant intermolecular $\mathrm{C}-\mathrm{H}$... O hydrogen bonds in the crystal. Two hydrogen bonds form an inversion dimer through the red spots (left part of Figure 5B) and an additional hydrogen bond links the dimer through another red spot in the $\mathrm{d}_{\text {norm }}$ Hirshfeld surface (right part of Figure $5 \mathrm{~B}$ ).

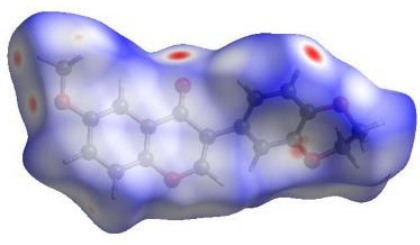

A

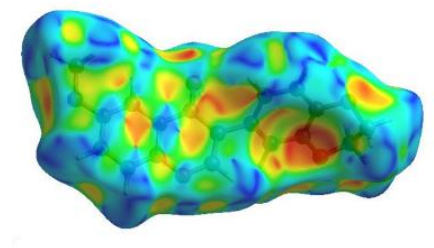

shape index

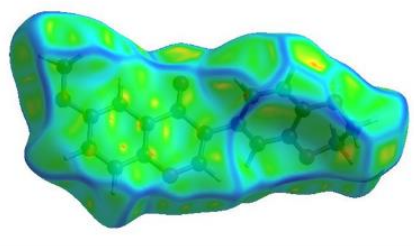

curvedness

Figure 5. Cont. 


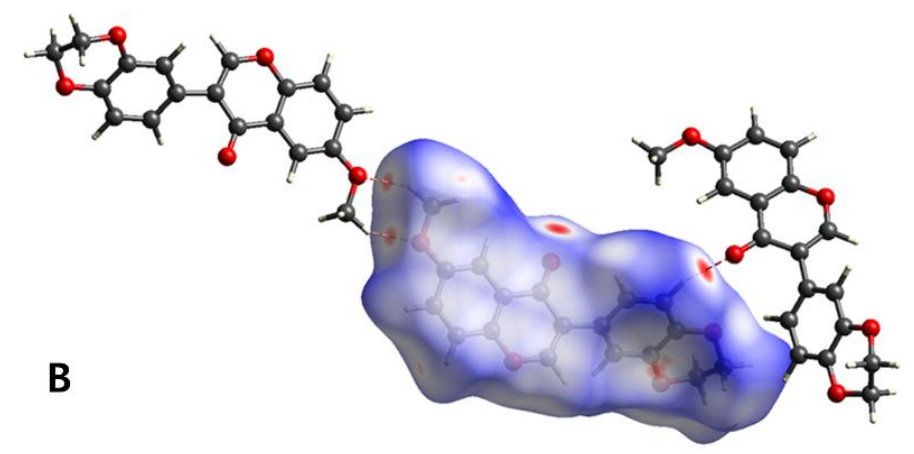

Figure 5. (A) Hirshfeld surfaces mapped with $d_{\text {norm, }}$, shape index and curvedness. (B) Deep red spots on the $d_{\text {norm }}$ surface represent close contact interactions with other molecules by dimeric linkage and H-bonds.

The Hirshfeld surfaces and their associated two-dimensional fingerprint plots were used to quantify various intermolecular interactions in the title compound. Therefore, two-dimensional fingerprint analysis was performed and the overall two-dimensional fingerprint plot, and those showing different contacts, are characterized in Figure 6a. Additional 2D fingerprint graphs give a summary of the relative contributions of intermolecular contacts in the crystal. Three major contributors to the total Hirshfeld surface are shown in Figure $6 \mathrm{~b}$. The most major $\mathrm{H} \cdots \mathrm{H} / \mathrm{H} \cdots \mathrm{H}$ interactions contribute $40.5 \%$ to the overall crystal packing and are depicted as points at $d i=1.1$ and $d e=1.3$ and vice versa. The contribution from the $\mathrm{O} \cdots \mathrm{H} / \mathrm{H} \cdots \mathrm{O}$ contacts are represented by a pair of sharp spikes characteristic of a strong hydrogen-bond interaction $(30.0 \%)$. The $\mathrm{C} \cdots \mathrm{H} / \mathrm{H} \cdots \mathrm{C}$ contacts in the structure have a symmetrical distribution of points $d i+d e=2.7 \AA$ with a $16.6 \%$ contribution to the Hirshfeld surface.

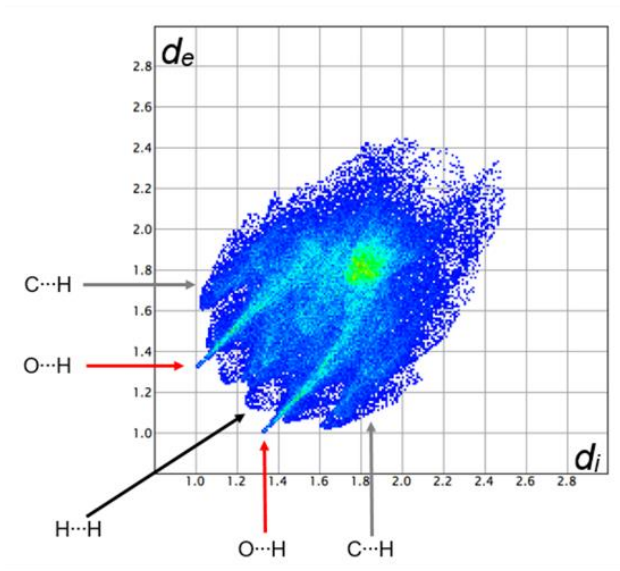

A
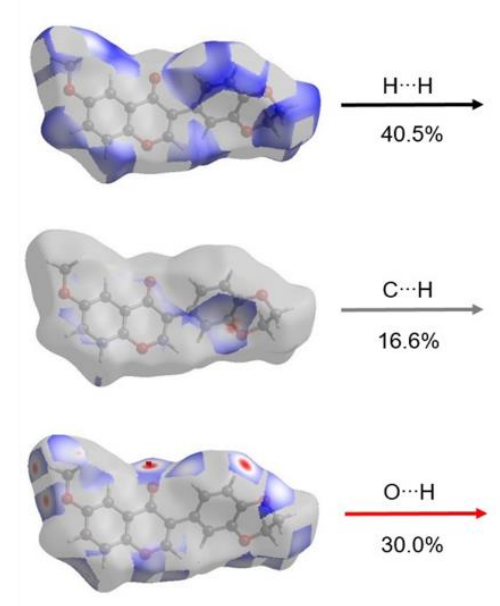

B

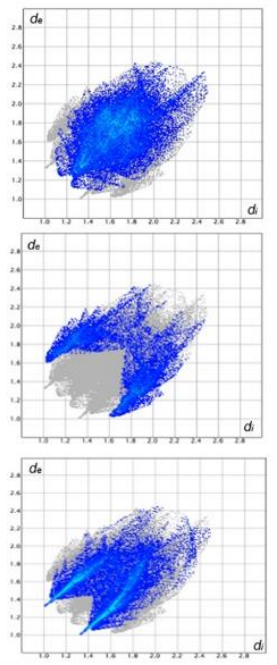

Figure 6. The two-dimensional fingerprint plots for isoflavone 6, showing all interactions (A), and delineated into a major contribution of $\mathrm{H} \cdots \mathrm{H} / \mathrm{H} \cdots \mathrm{H}, \mathrm{O} \cdots \mathrm{H} / \mathrm{H} \cdots \mathrm{O}, \mathrm{C} \cdots \mathrm{H} / \mathrm{H} \cdots \mathrm{C}$ interactions (B).

\subsection{DFT Calculation}

For the title compound 6, the molecular structure was calculated using the Gaussian 16 program (Gaussian-16; Revision A.03; Gaussian, Inc.: Wallingford, CT, USA, 2016) [30]. Full geometry optimization was performed using the density functional theory (DFT) Becke, 3-parameter, Lee-Yang-Parr (B3LYP) functional with the 6-311++G(d,p) basis set [31,32]. The molecular structure derived from the calculation is shown in Supplementary Figure S6 and calculated bond lengths and bond angles are presented in the Supplementary Tables S1 and S2. 
The geometrical values of the molecule observed from the X-ray crystallography experiment values were compared with those calculated. The experimental and calculated bond distances and bond angles show a good correlation, as shown in Figure 7.

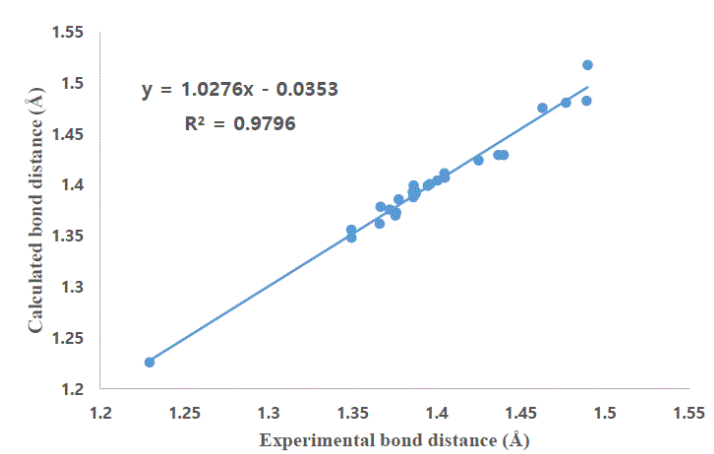

A

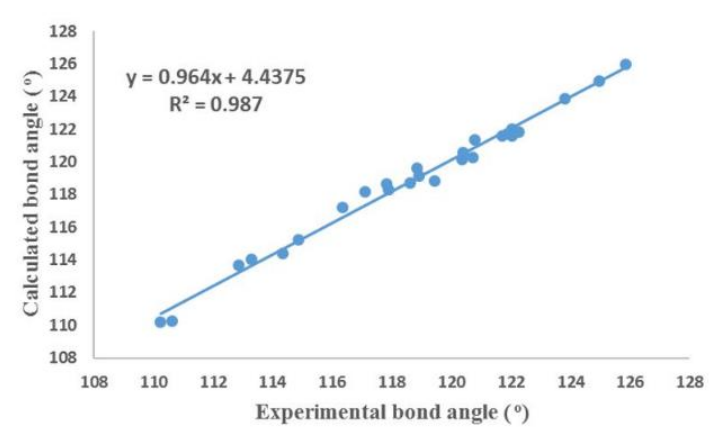

B

Figure 7. Correlation between the experimental and calculated bond lengths (A) and bond angles (B) of compound 6.

However, there were some discrepancies in the experimental and the calculation values of the dihedral angles, especially where free rotation is possible through C9-C11 single bonds. There are four combinations of dihedral angles around C9-C11 and the experimental, and the calculated dihedral angles (vacuum, DMSO) are shown in Table 4. A dihedral angle difference up to $7.5^{\circ}$ was observed. This difference is due to the fact that there is a packing effect in the crystal that is not considered in the calculation.

Table 4. Selected dihedral angles $\left(^{\circ}\right)$ for comparison between experimental and calculated values.

\begin{tabular}{cccc}
\hline \multirow{2}{*}{ Dihedral Angle } & Experimental & \multicolumn{2}{c}{ Calculated } \\
& Crystal & Vacuum & DMSO \\
\hline $\mathrm{C}(1)-\mathrm{C}(9)-\mathrm{C}(11)-\mathrm{C}(12)$ & 49.3755 & 42.4779 & 49.5214 \\
$\mathrm{C}(1)-\mathrm{C}(9)-\mathrm{C}(11)-\mathrm{C}(18)$ & -134.245 & -138.276 & -131.476 \\
$\mathrm{C}(8)-\mathrm{C}(9)-\mathrm{C}(11)-\mathrm{C}(12)$ & -129.908 & -137.454 & -131.062 \\
$\mathrm{C}(8)-\mathrm{C}(9)-\mathrm{C}(11)-\mathrm{C}(18)$ & 46.4713 & 41.7922 & 47.9409 \\
\hline
\end{tabular}

The optimized geometry in dimethyl sulfoxide (DMSO) solvent was calculated because real chemical reactions occur in a solution phase. The self-consistent reaction field (SCRF) technique was used to account for the solvent effect of DMSO. The polarizable continuum model (PCM) using the integral equation formalism variant (IEFPCM), which is the default SCRF method of the Gaussian 16 program, was used for the calculation [33].

The calculated bond lengths and bond angles in DMSO (Tables S1 and S2) are almost similar to those in vacuum. For the dihedral angles, especially for the angles around C9-C11, the calculated values in DMSO show better correspondence with the experiment, as shown in Table 4.

\subsection{Frontier Molecular Orbital Calculation}

Frontier molecular orbitals (FMOs) are used for calculating the most reactive site in the molecule and for describing various kinds of chemical reactions. The HOMO (highest occupied molecular orbital) and the LUMO (lowest unoccupied molecular orbital) are most important factors used as descriptors for the chemical reactions. HOMO has the most outer shell electrons and has a tendency to donate electrons as an electron donor. LUMO accept electrons for the reaction and is closely related to electron affinity. 
DFT calculations at the B3LYP/6-311++G(d,p) level (vacuum) disclosed that the HOMO is mainly localized on the 2,3-dihydrobenzo[b][1,4]dioxine region and LUMO on the $4 \mathrm{H}$-chromen-4-one group (Figure 8). The energy values of HOMO and LUMO were $-5.8223 \mathrm{eV}$ and $-1.8447 \mathrm{eV}$, and the calculated HOMO-LUMO energy gap was $3.9783 \mathrm{eV}$. The same calculations were performed in the DMSO condition because real chemical reactions occur in a solution state. Between the vacuum and DMSO environment, there is almost no difference in shape and energy of HOMO, LUMO and the HOMO-LUMO energy gap between the vacuum and DMSO environment (Figure S7, Supplementary Materials).

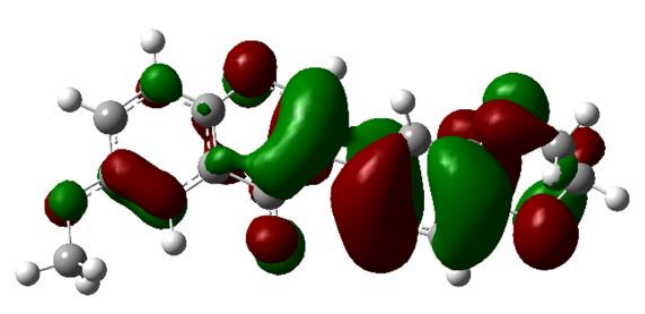

A

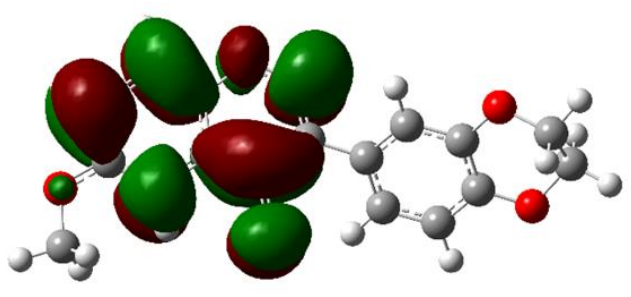

B

Figure 8. Molecular orbital surfaces of $\operatorname{HOMO}(\mathbf{A})$ and LUMO (B).

\subsection{Natural Population Analysis (NPA)}

The natural population analysis is an alternative to conventional Mulliken population analysis and gives a better description of the electron distribution and atomic charges in compounds [34]. The natural population analysis of the title molecule was carried out using an NBO 3.1 program [35]. The atomic charge distribution of the title compound $\mathbf{6}$ is shown in Figure 9. C2 is the most positive atom because it is connected with two electronegative oxygen atoms by a $\mathrm{C}=\mathrm{O}$ double bond, while $\mathrm{O} 1$, $\mathrm{O} 12, \mathrm{O} 16, \mathrm{O} 27$ and $\mathrm{O} 34$ are the most negative atoms in the compound $\mathbf{6}$.

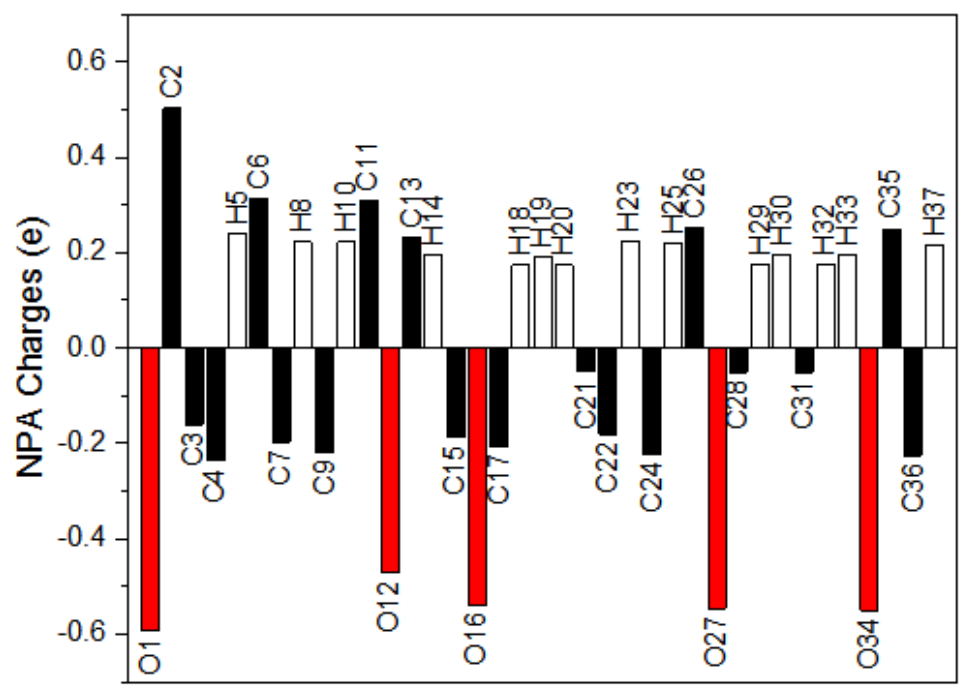

Figure 9. Atomic charge distribution of compound 6. The numbering of atoms in Figure 9 follows Supplementary Figure S6.

\subsection{In Silico Docking with Aurora Kinases}

First, the apo-protein of Aurora kinase A (AURKA) was obtained by removing the ligand contained in 3uod.pdb using the Sybyl program. For the flexible docking experiments, the apo-protein was submitted to energy minimization using the conjugate gradient algorithm, Tripos force field and Gasteiger-Hückell charges. The 3D structure of isoflavone 6 was adapted from the X-ray 
crystallographic structure determined in this research. The binding pocket of AURKA was determined using the LigPlot software as previously reported [36]. They are composed of 13 residues; Arg137, Leu139, Gly140, Val147, Ala160, Glu211, Tyr212, Ala213, Gly216, Thr217, Arg220, Glu 260 and Leu263. To confirm our flexible docking procedure was working well, the original ligand contained in 3uod.pdb, 4-[(4-\{[2-(trifluoromethyl)phenyl]amino\}pyrimidin-2-yl)amino]benzoic acid (named as 0c3), was docked in the apo-protein. Because 30 iterations were performed for the flexible docking, 30 complexes between the apo-protein and $0 \mathrm{c} 3$ were generated. Their binding energy ranged from -27.80 to $-19.83 \mathrm{kcal} / \mathrm{mol}$ and their binding poses were good enough to be comparable with 3uod.pdb.

Next, isoflavone 6 was docked into the apo-protein in the same manner as the original ligand. The binding energy generated by the 30 iterations ranged from -22.45 to $-17.66 \mathrm{kcal} / \mathrm{mol}$. The interactions between AURKA and isoflavone $\mathbf{6}$ were analyzed using the LigPlot program. Eleven residues including Leu139, Val147, Ala160, Lys162, Leu194, Leu210, Glu211, Pro214, Gly216, Arg220 and Leu263 showed the hydrophobic interactions with the ligand and three residues, including Arg137, Tyr212 and Ala213, formed hydrogen bonds (H-bonds) with the ligand. In the case of the original ligand, 0c3, 11 hydrophobic interactions (Leu139, Val147, Ala160, Leu194, Leu210, Glu211, Tyr212, Gly216, Leu263, Ala273 and Asp274) and two H-bonds (Arg137 and Ala213) were observed. The binding energy and the LigPlot analysis demonstrated that isoflavone 6 binds to AURKA on the same 11 residues out of 13 to which the original ligand binds. The binding mode of isoflavone 6 residing in AURKA was visualized using the PyMOL program (PyMOL Molecular Graphics System, version 1.0r1, Schrödinger, LLC, Portland, OR, USA). The binding patterns of isoflavone 6 (green color in Figure 10B) in Aurora kinase A is very similar to those of the original ligand (red color in Figure 10B), which may imply isoflavone 6 would be a good inhibitor of AURKA as an anti-cancer agent.
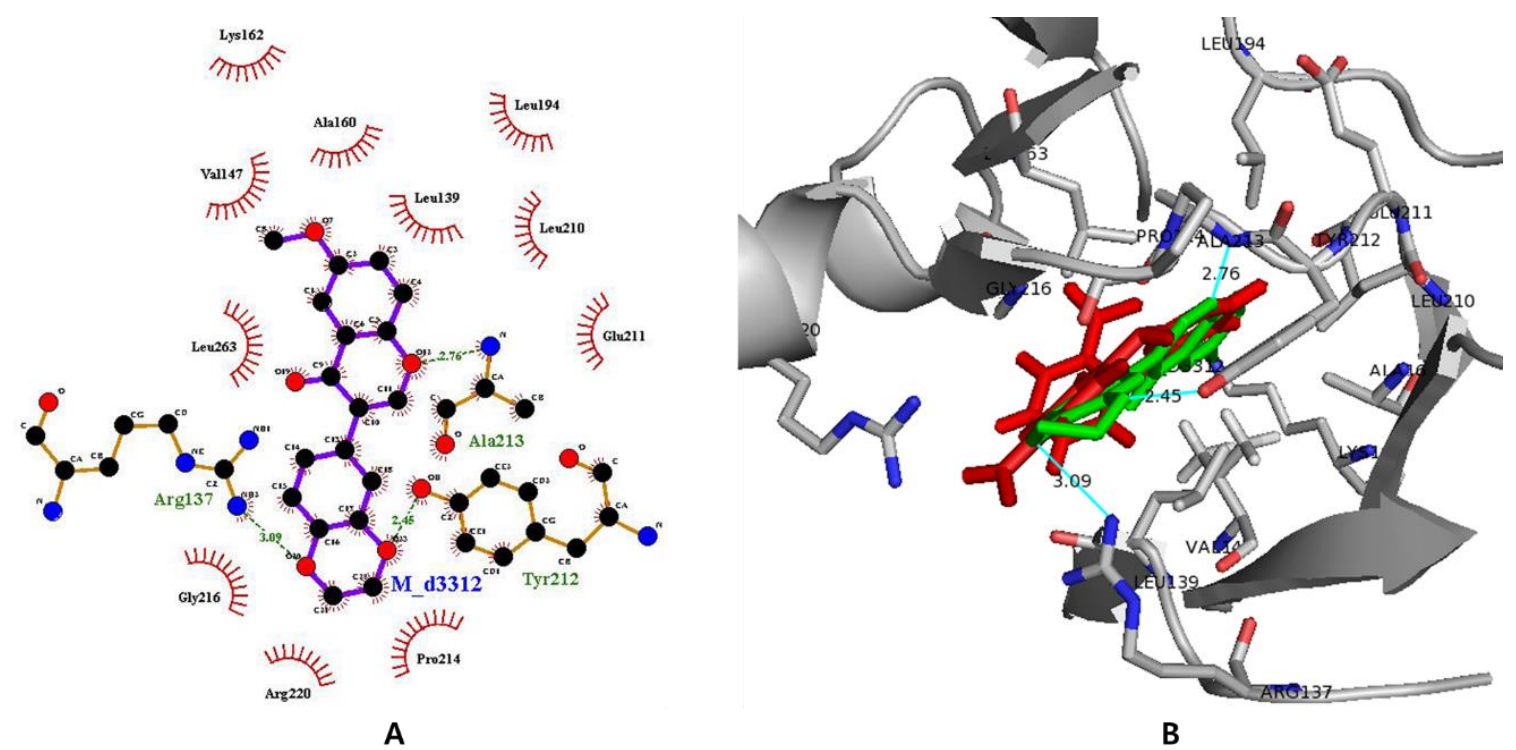

Figure 10. (A) The residues participating in the binding sites of the isoflavone 6-AURKA complex analyzed by using the LigPlot program. (B) Three-dimensional image of the Aurora kinase A and isoflavone $\mathbf{6}$ complex, where isoflavone $\mathbf{6}$ is colored in green and the original ligand $0 \mathrm{c} 3$ contained in 3uod.pdb is colored in red.

Like the AURKA docking procedure, the apo-protein of Aurora kinase B (AURKB) was obtained by removing its ligand 5-(2-(4-(cyclopropanecarboxamido)phenylthio)-6-(4-methylpiperazin1-yl)pyrimidin-4-ylamino)-1H-pyrazole-3-carboxamide (named as VX680) from 4af3.pdb, and the binding sites were determined using the LigPlot program. Nine residues including Leu83, Phe88, Val91, Ala104, Lys106, Tyr156, Pro158, Gly160 and Leu207 are involved in hydrophobic interactions with VX680, and two, Glu155 and Ala157, formed H-bonds with VX680. The binding energy between the apo-protein of $4 \mathrm{af3}$.pdb and VX680 ranged between -25.60 and $-13.36 \mathrm{kcal} / \mathrm{mol}$. The flexible docking 
of isoflavone 6 was carried out and its binding energy ranged between -22.19 and $-17.26 \mathrm{kcal} / \mathrm{mol}$. For the analysis of the docking result, the first complex between isoflavone $\mathbf{6}$ and AURKB was selected based on its binding energy and docking pose. It was confirmed that there were 11 residues, including Leu83, Va191, Ala104, Lys106, Leu138, Leu154, Glu155, Tyr156, Gly160, Lys164 and Leu207, that showed hydrophobic interactions with AURKB and two residues, Ala157 and Glu161, that formed H-bonds with AURKB. The residues participating in the binding of the isoflavone 6 in AURKB are visualized using LigPlot analysis in two dimensions and PyMOL in three dimensions. Isoflavone 6 (green color in Figure 11B) in Aurora kinase B showed binding patterns that is a little different from those of the original ligand 6 (red color in Figure 11B).
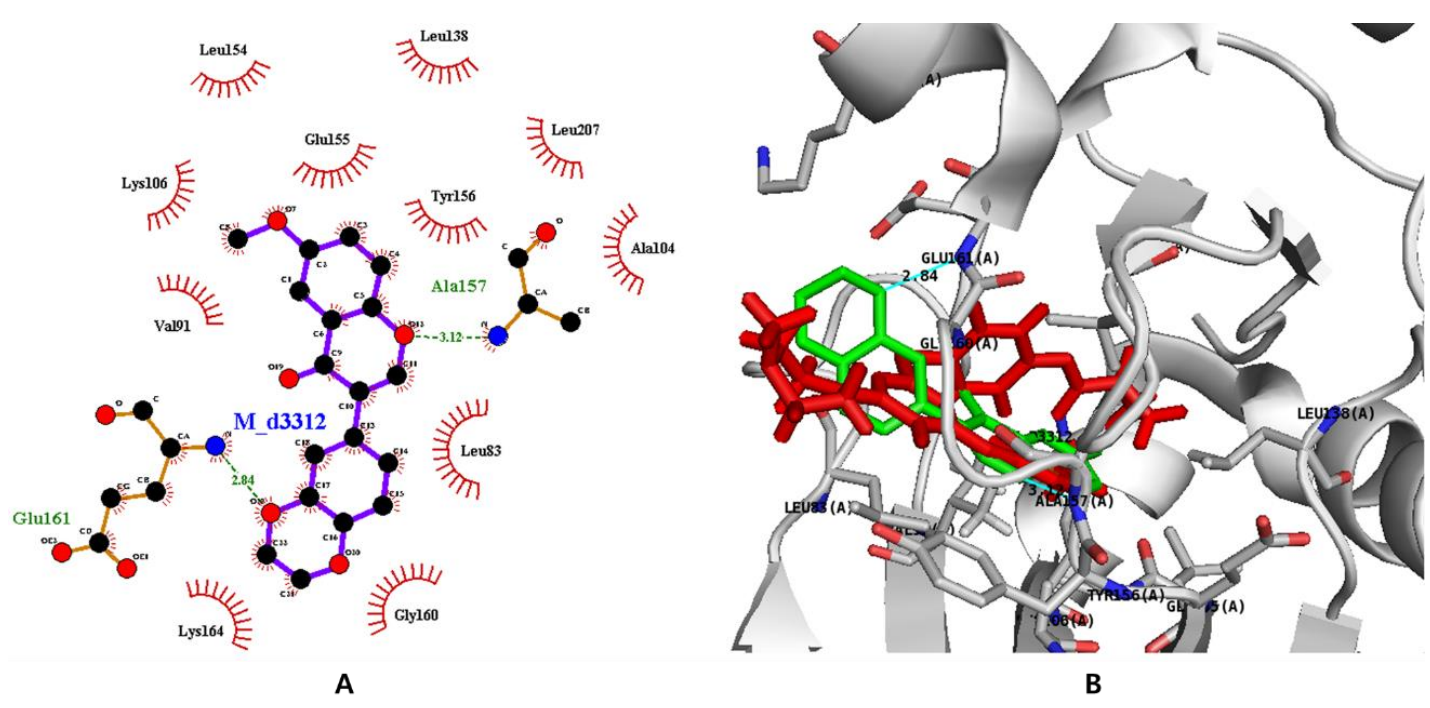

Figure 11. (A) The residues participating in the binding sites of the isoflavone 6 -AURKB complex analyzed by using the LigPlot program. (B) Three-dimensional image of the Aurora kinase B and isoflavone $\mathbf{6}$ complex, where isoflavone $\mathbf{6}$ is colored in green and the original ligand VX680 contained in 3uod.pdb is colored in red.

\subsection{Anti-Cancer Activity}

To measure the cytotoxicity of the compound against cancer cells, a clonogenic long-term survival assay was performed for HCT116 human colon cancer cells. Its detailed experimental procedures followed the methods reported previously [37]. HCT116 cell lines were treated with isoflavone 6 at different concentrations $(0,1,5,10$ and $20 \mu \mathrm{M})$. Its half-maximal cell growth inhibitory concentration $\left(\mathrm{GI}_{50}\right)$ was determined using SigmaPlot software (SYSTAT, Chicago, IL, USA) [38]. The cytotoxicity obtained from the clonogenic long-term survival assay against HCT116 human colon cancer cells is shown in Figure 12. Its $\mathrm{GI}_{50}$ value was determined to be $24.9 \mu \mathrm{M}$.

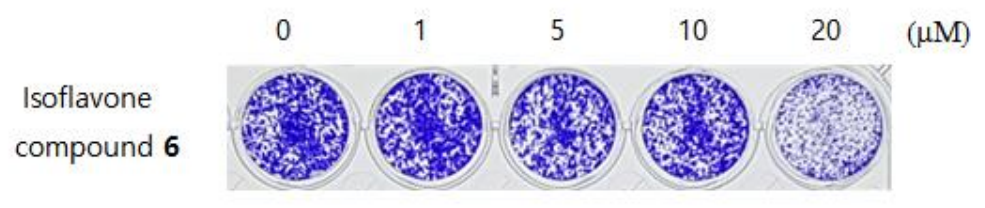

Figure 12. Effect of isoflavone 6 on the inhibition of clonogenicity of HCT116 colon cancer cells.

\section{Conclusions}

The novel isoflavone compound, 3-(2,3-dihydrobenzo[b][1,4]dioxin-6-yl)-6-methoxy-4H-chromen4-one (6) was synthesized in order to find a lead product for Aurora kinase inhibitor as an anti-cancer agent. The three-dimensional structure of 6 was confirmed by single crystal X-ray diffraction. In the crystal, pairs of $\mathrm{C}-\mathrm{H} \cdots \mathrm{O}$ hydrogen bonds form inversion dimers which are linked each other by 
additional hydrogen bonds and involved in the formation of three-dimensional networks. Hirshfeld surface analyses were used to study the intermolecular interactions. Two-dimensional fingerprint plots showed that the interactions of $\mathrm{H} \cdots \mathrm{H}, \mathrm{O} \cdots \mathrm{H}, \mathrm{C} \cdots \mathrm{H}$ are the major contributions of intermolecular contacts in the crystal. The geometric parameters obtained using the DFT/B3LYP functional with $6-311++G(d, p)$ basis set are consistent with the results from the crystal structure analyses. Isoflavone 6 showed cytotoxicity against HCT116 human colon cancer cells with a $\mathrm{GI}_{50}$ value of $24.9 \mu \mathrm{M}$. Molecular docking was used to predict the protein-ligand binding mode against Aurora kinase A and B. A LigPlot analysis revealed that isoflavone 6 fitted into the binding pocket of Aurora kinase A as well as the original ligand.

Supplementary Materials: The following are available online at http://www.mdpi.com/2073-4352/10/5/413/s1, Figures S1-S5: NMR spectra and Mass spectrum, Figures S6 and S7, Tables S1-S4: DFT calculation results including bond lengths, bond angles, dihedral angles, NPA charge, HOMO and LUMO.

Author Contributions: Conceptualization, D.K. and S.Y.S.; investigation, S.A., J.H.L. and M.Y.; validation, J.S. and Y.L.; writing — original draft, D.K. writing—-review and editing, S.Y.S. All authors have read and agreed to the published version of the manuscript.

Funding: The authors acknowledge financial support from the Basic Science Research Program (award No. NRF2019R1F1A1058747). S.Y. Shin was supported by the KU Research Professor Program of Konkuk University.

Conflicts of Interest: The authors declare no conflict of interest.

\section{References}

1. Liu, J.; Taylor, S.F.; Dupart, P.S.; Arnold, C.L.; Sridhar, J.; Jiang, Q.; Wang, Y.; Skripnikova, E.V.; Zhao, M.; Foroozesh, M. Pyranoflavones: A group of small-molecule probes for exploring the active site cavities of cytochrome P450 enzymes 1A1, 1A2, and 1B1. J. Med. Chem. 2013, 56, 4082-4092. [CrossRef]

2. Cushnie, T.P.T.; Lamb, A.J. Antimicrobial activity of flavonoids. Int. J. Antimicrob. Agents 2005, 26, 343-356. [CrossRef] [PubMed]

3. Nijveldt, R.J.; van Nood, E.; van Hoorn, D.E.; Boelens, P.G.; van Norren, K.; van Leeuwen, P.A. Flavonoids: A review of probable mechanisms of action and potential applications. Am. J. Clin. Nutr. 2001, 74, 418-425. [CrossRef] [PubMed]

4. Shukla, S.; Gupta, S. Apigenin: A promising molecule for cancer prevention. Pharm. Res. 2010, 27, 962-978. [CrossRef] [PubMed]

5. Lebeau, J.; Furman, C.; Bernier, J.L.; Duriez, P.; Teissier, E.; Cotelle, N. Antioxidant properties of di-tert-butylhydroxylated flavonoids. Free Radic. Biol. Med. 2000, 29, 900-912. [CrossRef]

6. Park, W.H. MAPK inhibitors differentially affect gallic acid-induced human pulmonary fibroblast cell growth inhibition. Mol. Med. Rep. 2011, 4, 193-204. [CrossRef] [PubMed]

7. Medzhitov, R. Inflammation 2010: New adventures of an old flame. Cell 2010, 140, 771-776. [CrossRef] [PubMed]

8. Wang, S.Q.; Han, X.Z.; Li, X.; Ren, D.M.; Wang, X.N.; Lou, H.X. Flavonoids from Dracocephalum tanguticum and their cardioprotective effects against doxorubicin-induced toxicity in H9c2 cells. Bioorg. Med. Chem. Lett. 2010, 20, 6411-6415. [CrossRef]

9. Gaspar, A.; Matos, M.J.; Garrido, J.; Uriarte, E.; Borges, F. Chromone: A valid scaffold in medicinal chemistry. Chem. Rev. 2014, 114, 4960-4992. [CrossRef]

10. Singh, M.; Kaur, M.; Silakari, O. Flavones: An important scaffold for medicinal chemistry. Eur. J. Med. Chem. 2014, 84, 206-239. [CrossRef]

11. Barakat, A.; Soliman, A.M.; El-Faham, A.; Ali, M.; Al-Majid, A.M.; Yousuf, S.; Choudhary, M.I. Three multi-components reaction: Synthesis and X-ray single-crystal of hydroacridinone-based hydrazino-s-triazine derivative as a new class of urease inhibitor. Crystals 2020, 10, 14. [CrossRef]

12. Al-Wabli, R.I.; Al-Ghamdi, A.R.; Aswathy, S.V.; Ghabbour, H.A.; Al-Agamy, M.H.; Hubert Joe, I.H.; Attia, M.I. Synthesis, single crystal X-ray structure, DFT computations, hirshfeld surface analysis and molecular docking simulations on (\{[(1E)-1-(1,3-Benzodioxol-5-yl)-3-(1H-imidazol-1-yl) propylidene]amino\}oxy)(furan-2-yl)methanone: A new antifungal agent. Crystals 2019, 9, 25. [CrossRef] 
13. Joubert, J. Synthesis, crystal structure, DFT studies, docking, studies, and fluorescent properties of 2-(Adamantan-1-yl)-2H-isoindole-1-carbonitrile. Crystals 2019, 9, 24. [CrossRef]

14. Shin, S.Y.; Lee, Y.; Kim, B.S.; Lee, J.; Ahn, S.; Koh, D.; Lim, Y.; Lee, Y.H. Inhibitory effect of synthetic flavone derivatives on pan-aurora kinases: Induction of G2/M cell-cycle arrest and apoptosis in HCT116 human colon cancer cells. Int. J. Mol. Sci. 2018, 19, 86. [CrossRef]

15. Ahn, S.; Ahn, E.; Sung, J.; Koh, D.; Lim, Y.; Park, S. Synthetic polyphenol compounds inhibit $\beta$-catenin/Tcf signaling: Structure-activity relationship. J. Ind. Eng. Chem. 2017, 56, 258-269. [CrossRef]

16. Lee, K.; Lee, D.H.; Jung, Y.J.; Shin, S.Y.; Koh, D.; Lee, Y.H. A methoxyflavanone derivative, $2^{\prime}, 3^{\prime}, 4^{\prime}$-trimethoxy-5,6-naphthoflavanone, inhibits proliferation of HCT116 human colon cancer cells by inducing G2/M cell cycle arrest and apoptosis. Appl. Biol. Chem. 2016, 59, 249-253. [CrossRef]

17. Sophors, P.; Kim, Y.M.; Seo, G.Y.; Huh, J.S.; Lim, Y.; Koh, D.S.; Cho, M. A synthetic isoflavone, DCMF, promotes human keratinocyte migration by activating Src/FAK signaling pathway. Biochem. Biophys. Res. Commun. 2016, 472, 332-338. [CrossRef]

18. Ahn, S.; Shin, S.Y.; Jung, Y.; Jung, H.; Kim, B.S.; Koh, D.; Lim, Y. (1) H and (13) C NMR spectral assignments of novel flavonoids bearing benzothiazepine. Magn. Reson. Chem. 2016, 54, 382-390. [CrossRef]

19. Bruker. APEX2, SAINT and SADABS; Bruker AXS Inc.: Madison, WI, USA, 2012.

20. Sheldrick, G.M. Crystal structure refinement with SHELXL. Acta. Cryst. C 2015, 71, 3-8. [CrossRef]

21. Martin, M.P.; Zhu, J.Y.; Lawrence, H.R.; Pireddu, R.; Luo, Y.; Alam, R.; Ozcan, S.; Sebti, S.M.; Lawrence, N.J.; Schonbrunn, E. A novel mechanism by which small molecule inhibitors induce the DFG flip in Aurora A. ACS Chem. Biol. 2012, 7, 698-706. [CrossRef]

22. Fancelli, D.; Moll, J.; Varasi, M.; Bravo, R.; Artico, R.; Berta, D.; Bindi, S.; Cameron, A.; Candiani, I.; Cappella, P.; et al. 1,4,5,6-tetrahydropyrrolo[3,4-c]pyrazoles: Identification of a potent Aurora kinase inhibitor with a favorable antitumor kinase inhibition profile. J. Med. Chem. 2006, 49, 7247-7251. [CrossRef] [PubMed]

23. Elkins, J.M.; Santaguida, S.; Musacchio, A.; Knapp, S. Crystal structure of human aurora B in complex with INCENP and VX-680. J. Med. Chem. 2012, 55, 7841-7848. [CrossRef]

24. Biegasiewicz, K.F.; Gordon, J.S.; Rodriguez, D.A.; Priefer, R. Development of a general approach to the synthesis of a library of isoflavonoid derivatives. Tetrahedron Lett. 2014, 55, 5210-5212. [CrossRef]

25. Liu, L.; Zhang, Y.; Wang, Y. Phosphine-free palladium acetate catalyzed Suzuki reaction in water. J. Org. Chem. 2005, 70, 6122-6125. [CrossRef] [PubMed]

26. Ahn, S.; Lim, Y.; Koh, D. Crystal structure of 2-(2,3-di-meth-oxy-naphthalen-1-yl)-3-hy-droxy-6-meth-oxy-4Hchromen-4-one. Acta. Cryst. E Cryst. Commun. 2015, 71, o842-o843. [CrossRef] [PubMed]

27. Yoo, J.S.; Lim, Y.; Koh, D. Crystal structure of 2-(3,4-di-meth-oxy-phen-yl)-3-hy-droxy-4H-chromen-4-one. Acta. Cryst. Sect. E Struct. Rep. Online 2014, 70, o999-o1000. [CrossRef]

28. Turner, M.J.; McKinnon, J.J.; Wolff, S.K.; Grimwood, D.J.; Spackman, P.R.; Jayatilaka, D.; Spackman, M.A. CrystalExplorer17; University of Western Australia: Crawley, Australia, 2017.

29. McKinnon, J.J.; Jayatilaka, D.; Spackman, M.A. Towards quantitative analysis of intermolecular interactions with Hirshfeld surfaces. Chem. Commun. 2007, 37, 3814-3816. [CrossRef]

30. Frisch, M.J.; Trucks, G.W.; Schlegel, H.B.; Scuseria, G.E.; Robb, M.A.; Cheeseman, J.R.; Scalmani, G.; Barone, V.; Mennucci, B.; Petersson, G.A.; et al. Gaussian 16, Revision A.03; Gaussian Inc.: Wallingford, CT, USA, 2016.

31. Petersson, G.A.; Allaham, M.A. A complete basis set model chemistry. II. Open-shell systems and the total energies of the first-row atoms. J. Chem. Phys. 1991, 94, 6081-6091. [CrossRef]

32. Becke, A.D. Density-functional thermochemistry. III. The role of exact exchange. J. Chem. Phys. 1993, 98, 5648-5652. [CrossRef]

33. Tomasi, J.; Mennucci, B.; Cammi, R. Quantum mechanical continuum solvation models. Chem. Rev. 2005, 105, 2999-3093. [CrossRef]

34. Reed, A.E.; Weinstock, R.B.; Weinhold, F. Natural population analysis. J. Chem. Phys. 1985, 83, 735-746. [CrossRef]

35. Glendening, E.D.; Reed, A.E.; Carpenter, J.E.; Weinhold, F. NBO Version 3.1.; Gaussian Inc.: Wallingford, CT, USA, 2016.

36. Jung, K.Y.; Park, J.; Han, Y.S.; Lee, Y.H.; Shin, S.Y.; Lim, Y. Synthesis and biological evaluation of hesperetin derivatives as agents inducing apoptosis. Bioorg. Med. Chem. 2017, 25, 397-407. [CrossRef] [PubMed] 
37. Franken, N.A.; Rodermond, H.M.; Stap, J.; Haveman, J.; van Bree, C. Clonogenic assay of cells in vitro. Nat. Protoc. 2006, 1, 2315-2319. [CrossRef] [PubMed]

38. Kim, B.S.; Shin, S.Y.; Ahn, S.; Koh, D.; Lee, Y.H.; Lim, Y. Biological evaluation of 2-pyrazolinyl-1-carbothioamide derivatives against HCT116 human colorectal cancer cell lines and elucidation on QSAR and molecular binding modes. Bioorg. Med. Chem. 2017, 25, 5423-5432. [CrossRef] 